\title{
Author Correction: Convergent evolution of a modified, acetate-driven TCA cycle in bacteria
}

\author{
Waldan K. Kwong, Hao Zheng and Nancy A. Moran
}

Correction to: Nature Microbiology https://doi.org/10.1038/nmicrobiol.2017.67, published online 28 April 2017.

In this Brief Communication, the authors omitted references to several previous studies that have demonstrated that the TCA variant shown has also been found in several other bacterial species, specifically among some anaerobic Deltaproteobacteria. The Brief Communication focused on showing that this variant is more widespread than previously known, particularly in animal-associated bacteria. Using genetic approaches, Kwong et al. demonstrated this alternative cycle in additional, distantly related organisms. Thus, the previous work does not affect the results of the advance provided. However, the previous studies are relevant to this topic and should have been cited, and Kwong et al. apologize for this for the omission. Citations to several of the studies should have been included as refs ${ }^{9-13}$ in the text as shown below.

Original sentence:

Another variant cycle was identified in Acetobacter aceti, in which succinyl-CoA is converted to succinate by an acetate:succinate CoA-transferase (ASCT) instead of the typical succinyl-CoA synthetase (SCS) ${ }^{7,8}$.

Corrected sentence:

Another variant cycle was identified in Acetobacter aceti ${ }^{7,8}$ and some anaerobic Deltaproteobacteria ${ }^{9-13}$, whereby succinyl-CoA is converted to succinate by an acetate:succinate CoA-transferase (ASCT) instead of the typical succinyl-CoA synthetase (SCS).

\section{References}

9. Gebhardt, N. A., Linder, D. \& Thauer, R. K. Anaerobic acetate oxidation to $\mathrm{CO}_{2}$ by Desulfobacter postgatei. Arch. Microbiol. 136, 230-233 (1983).

10. Schauder, R., Widdel, F. \& Fuchs, G. Carbon assimilation pathways in sulfate-reducing bacteria II. Enzymes of a reductive citric acid cycle in the autotrophic Desulfobacter hydrogenophilus. Arch. Microbiol. 148, 218-225 (1987).

11. Möller, D., Schauder, R., Fuchs, G. \& Thauer, R. K. Acetate oxidation to $\mathrm{CO}_{2}$ via a citric acid cycle involving an ATP-citrate lyase: a mechanism for the synthesis of ATP via substrate level phosphorylation in Desulfobacter postgatei growing on acetate and sulfate. Arch. Microbiol. 148, 202-207 (1987).

12. Thauer, R. K., Möller-Zinkhan, D. \& Spormann, A. M. Biochemistry of acetate catabolism in anaerobic chemotrophic bacteria. Annu. Rev. Microbiol. 43, 43-67 (1989).

13. Thauer, R. K. Citric-acid cycle, 50 years on. Modifications and an alternative pathway in anaerobic bacteria. Eur. J. Biochem. 176, 497-508 (1988).

Published online: 27 June 2018

https://doi.org/10.1038/s41564-018-0195-6 